\title{
Expression of the fts $Y$ gene, encoding a homologue of the $\alpha$ subunit of mammalian signal recognition particle receptor, is controlled by different promoters in vegetative and sporulating cells of Bacillus subtilis
}

\author{
Hiroshi Kakeshita, Akihiro Oguro, Reiko Amikura, Kouji Nakamura \\ and Kunio Yamane
}

\begin{abstract}
Author for correspondence: Kunio Yamane. Tel: +8129853 6680. Fax: +81298536680. e-mail:kyamane@sakura.cc.tsukuba.ac.jp
\end{abstract}

Institute of Biological Sciences, University of Tsukuba, Tsukuba-shi, Ibaraki 305, Japan

\begin{abstract}
Bacillus subtilis FtsY (Srb) is a homologue of the $\alpha$ subunit of the receptor for mammalian signal-recognition particle (SRP) and is essential for protein secretion and vegetative cell growth. The fts $Y$ gene is expressed during both the exponential phase and sporulation. In vegetative cells, fts $Y$ is transcribed with two upstream genes, rncS and smc, that are under the control of the major transcription factor $\sigma^{\mathrm{A}}$. During sporulation, Northern hybridization detected fts $Y$ mRNA in wild-type cells, but not in sporulating cells of $\sigma^{\mathrm{K}}$ and gerE mutants. Therefore, fts $Y$ is solely expressed during sporulation from a $\sigma^{\mathrm{K}}$ - and GerE-controlled promoter that is located immediately upstream of fts $Y$ inside the smc gene. To examine the role of Fts $Y$ during sporulation, the $B$. subtilis strain ISR39 was constructed, a fts $Y$ conditional mutant in which fts $Y$ expression can be shut off during spore formation but not during the vegetative state. Electron microscopy showed that the outer coat of ISR39 spores was not completely assembled and immunoelectron microscopy localized FtsY to the inner and outer coats of wild-type spores.
\end{abstract}

Keywords: Bacillus subtilis, FtsY (Srb), gene expression, $\sigma^{\mathrm{K}}$ and GerE, immunoelectron microscopy

\section{INTRODUCTION}

The signal-recognition particle (SRP) and the SRP receptor play a central role in targeting presecretory proteins to the membrane of the endoplasmic reticulum in mammalian cells. Recent genetic and biochemical evidence indicates that targeting may also be mediated by SRP in bacteria (Lütcke, 1995; Schatz \& Dobberstein, 1996; Fekkes \& Driessen, 1999). Bacillus subtilis is a Gram-positive bacterium that secretes high levels of extracellular enzymes into the culture medium. In $B$. subtilis, small cytoplasmic RNA and Ffh are homologues of SRP 7S RNA and SRP54 protein (a $54 \mathrm{kDa}$ subunit of SRP), respectively (Honda et al., 1993; Struck et al., 1989). These are essential for protein translocation and the normal growth of $B$. subtilis (Honda et al., 1993; Nakamura et al., 1992). We cloned a gene for a homologue of the $\alpha$ subunit of the SRP receptor

Abbreviation: SRP, signal recognition particle.
$(\mathrm{SR} \alpha)$ and designated it srb (Oguro et al., 1995). The $\operatorname{srb}$ gene was renamed $f t s \mathrm{Y}$ in the $B$. subtilis genome project since the amino acid sequence of Srb has $49.7 \%$ identity to that of E. coli FtsY (Kunst et al., 1997). During the vegetative stage, $f t s Y$ is transcribed with the upstream genes, $r n c S$ (ribonuclease III) and $s m c$ (a homologue of the SMC family protein), under the control of the major transcription factor $\sigma^{\mathrm{A}}$. Depleting $f t s Y$ in Bacillus subtilis inhibits normal cell growth and leads to a substantial loss of $\beta$-lactamase translocation (Oguro et al., 1995, 1996), indicating that FtsY is essential for protein translocation.

B. subtilis generates a heat-resistant endospore under poor nutrient conditions. During sporulation, the forespore and mother cell each contain a chromosome and engage in a specific and genetic program via four compartment-specific $\sigma$ subunits of RNA polymerase. Forespore-specific gene expression is controlled by $\sigma^{\mathrm{F}}$ and $\sigma^{\mathrm{G}}$. Activation of $\sigma^{\mathrm{E}}$ in the mother cell is followed by the synthesis and activation of $\sigma^{\mathrm{K}}$. In addition, two small 
DNA-binding proteins, SpoIIID and GerE, activate or repress the transcription of many mother cell-specific genes. Mother-cell transcription factors form a hierarchical regulatory cascade in which the synthesis of each factor depends upon the activity of the prior factor, in the order $\sigma^{\mathrm{E}}$, SpoIIID, $\sigma^{\mathrm{K}}$ and GerE (Losick \& Stragier, 1992; Stragier \& Losick, 1996). During the assembly of the cortex and coat proteins in the forespore, a number of polypeptides and proteins are synthesized within the mother cell and deposited on the forespore (Stragier \& Losick, 1996). However, little is known about the role of the protein-secretion machinery in spore formation.

The present study shows that, in addition to the expression of $f t s \mathrm{Y}$ in vegetative cells by the $\sigma^{\mathrm{A}}$ promoter, $f t s Y$ is expressed solely at $t_{8}$ during sporulation (times are given as hours after the onset of sporulation; i.e. $t_{8}$ is $8 \mathrm{~h}$ after the onset of sporulation), from a promoter that is controlled by $\sigma^{\mathrm{K}}$ and GerE, and located immediately upstream of $f t s Y$ and inside the $s m c$ gene. Electron microscopy showed that the outer coat of the $f t s Y$ mutant spores is composed of thin layers and immunoelectron microscopy localized FtsY to the coat.

\section{METHODS}

Bacterial strains and media. The B. subtilis strains listed in Table 1 were maintained and cultured in Luria-Bertani (LB) medium. Bacterial cells were cultivated in Schaeffer medium (Schaeffer et al., 1965) with vigorous shaking to induce sporulation. B. subtilis ISR39 (trpC2 srb::pMT3ftsY) was constructed from B. subtilis 168 by homologous recombi- nation between the chromosome and the plasmid pMT3ftsY, carrying another truncated $f t s Y$ gene, as described below.

Plasmid construction. To construct B. subtilis ISR39, an fts $Y$ conditional null mutant, pMT3FtsY was derived from pMutinT3 (Moriya et al., 1998), which contains a plasmid origin of replication that functions only in Escherichia coli, the spac-1 promoter, the lacl gene expressed by the penP promoter, the $\mathrm{erm} C$ gene and three $\rho$-independent transcriptional terminators in front of spac-1. A $434 \mathrm{bp}$ DNA fragment containing the flanking and $\mathrm{N}$-terminal portions of $f t s Y$ (134 aa) was synthesized by the PCR using the synthetic oligonucleotides PS-1 (5'-CTATACAGCCAAGCTTGAATTCGTTCAGTAACGAGG-3', generating a HindIII restriction site) and PS-2 (5'-CGCATTATGGGGATCCGTTTTCCCGACGCCGTTTAC-3', generating a BamHI restriction site) at positions 4915-4933 and 5330-5349, respectively, in the DNA sequence reported by Oguro et al. (1996). The amplified fragment was digested with HindIII/BamHI, then ligated into pMutinT3 that had been digested with the same enzymes. The construct in which the ribosome-binding sequence and the truncated $f t s Y$ gene were positioned downstream of three $\rho$-independent transcriptional terminators and the spac-1 promoter was designated pMT3FtsY.

RNA preparation and Northern hybridization. Total RNAs of B. subtilis cells cultured in Schaeffer medium were extracted at various vegetative and sporulating stages as described by Igo \& Losick (1986). Northern hybridization proceeded according to a modification of the method described by Sambrook et al. (1989). Total RNA $(10 \mu \mathrm{g})$ was resolved by electrophoresis through a $1.5 \%$ agarose gel containing $2.2 \mathrm{M}$ formaldehyde, then transferred to Gene Screen Plus nylon membranes (NEN Research Products). Prehybridization and hybridization proceeded at $65^{\circ} \mathrm{C}$ in hybridization buffer $(0.9 \mathrm{M} \mathrm{NaCl}, 0.09 \mathrm{M}$ sodium citrate, $2 \times$ Denhardt's reagent, $0 \cdot 1 \%$ SDS, $100 \mu \mathrm{g}$ salmon sperm DNA ml-1). To isolate DNA probes for $f t s Y$, a

Table 1. Bacterial strains and plasmids used in this study

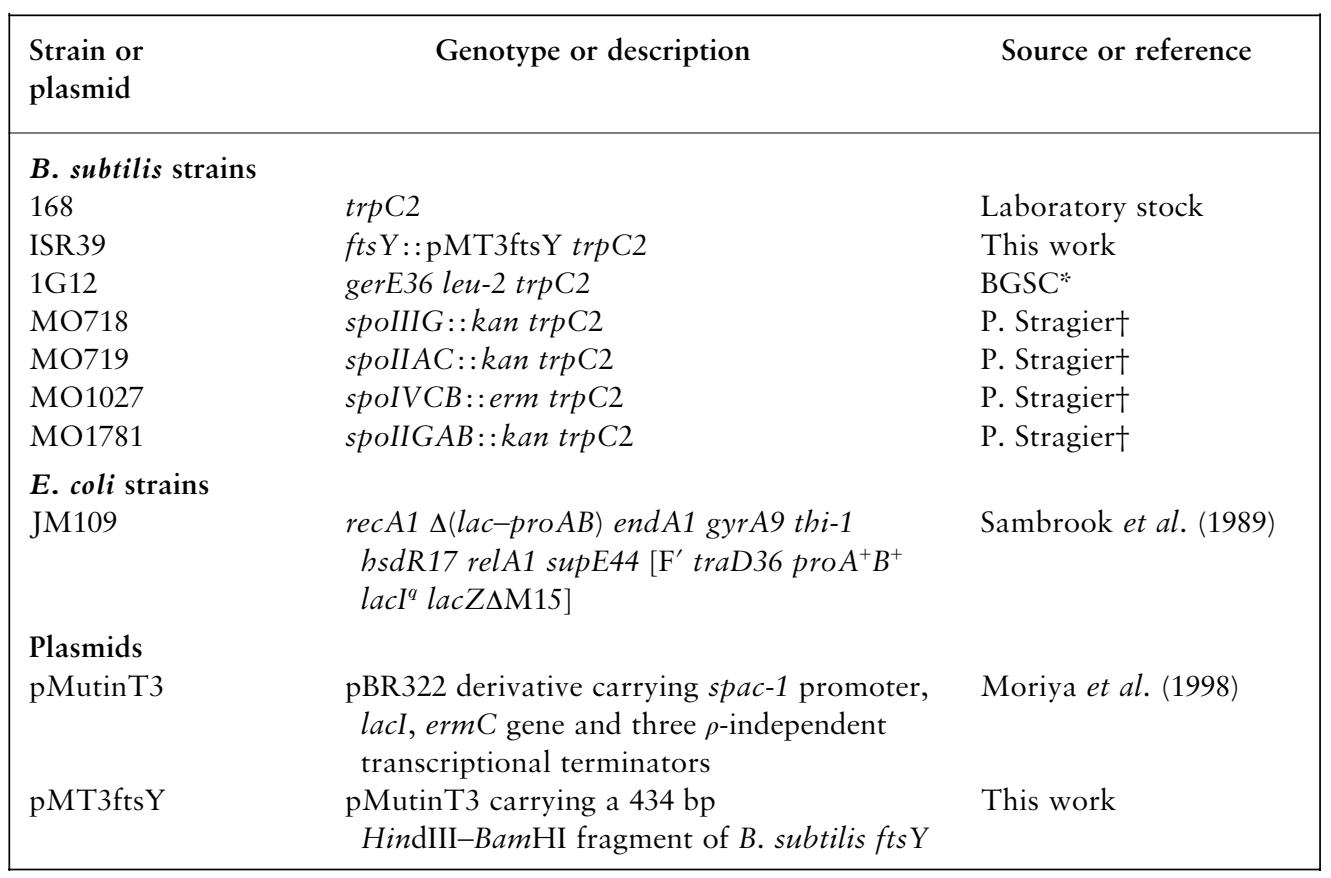

* BGSC, Bacillus Genetic Stock Center.

† Institut de Biologie Physico-Chimique, Paris, France. 
$1 \cdot 0 \mathrm{~kb}$ DNA region of $f t s Y$ was amplified by PCR using the synthetic oligonucleotides PS-3 (5'-AAAGAGGTTAAAAGATGAGCTT-3') and PS-4 (5'-GCCTATCAAGTAAGAAGATA-3') at positions 4935-4956 and 5995-5976, respectively, of the DNA sequence reported by Oguro et al. (1996). A $1 \cdot 1 \mathrm{~kb}$ fragment of $\cot \mathrm{YZ}$ was amplified using PC-1 (5'-ATGATGTGTACGATTGATTA-3') and PC-2 (5'-ATATATAGACGTTCACCCAC-3') at positions 2720-2701 and 1571-1590 of the sequence described by Zhang et al. (1993), and $0.6 \mathrm{~kb}$ of $\cot Z$ was amplified using PC- 1 and PC-3 $\left(5^{\prime}\right.$-AAACACTTGTAAAGAGGAAT-3') at position 2151-2170 of the latter sequence (Zhang et al., 1993). The PCR template was chromosomal DNA of B. subtilis 168 . After purification by agarose gel electrophoresis, the amplified DNA fragments were labelled with ${ }^{32} \mathrm{P}$ using a random primer DNA labelling kit (Takara Shuzo) and used as hybridization probes.

Mapping the $\mathbf{5}^{\prime}$ terminus of $\mathrm{fts} Y$ mRNA during sporulation. Primer extension proceeded using the synthetic oligonucleotide $\operatorname{Pr}\left(5^{\prime}\right.$-ACCCTCTCAAACTCATCTAT-3') at position 4358-4339 of the nucleotide sequence reported by Oguro et al. (1996). The RNAs to be tested $(40 \mu \mathrm{g})$ and $5 \times 10^{4}$ c.p.m. ${ }^{32} \mathrm{P}$-labelled oligonucleotide primer were hybridized at $40{ }^{\circ} \mathrm{C}$ overnight. Rous-associated virus- 2 reverse transcriptase was added and the mixture was incubated at $42{ }^{\circ} \mathrm{C}$ for $1 \mathrm{~h}$. The reaction products were resolved on DNA sequencing gels. The $5^{\prime}$ ends of $f t s Y$-specific mRNAs were determined by comparison with sequencing ladders generated from an M13 clone that included a $1.6 \mathrm{~kb}$ DNA fragment of the upstream gene $(s m c)$ of $f t s \mathrm{Y}$ using the Pr oligonucleotide primer. A $1.6 \mathrm{~kb}$ DNA fragment was synthesized by PCR using synthetic oligonucleotides PS-5 (5'-CCTCTGTATCAGGCACC-3') and PS-6 (5'-CAGGAGGATCCAGTTTTGCAG-3', generating a BamHI restriction site) at positions 3279-3295 and 4635-4615, respectively, in the DNA sequence reported by Oguro et al. (1996). The amplified fragment was digested by DraI/BamHI and ligated into M13 digested with HincII/ BamHI.

Preparation of cell lysates from sporulating cells. Sporangia of $B$. subtilis growing in Schaeffer medium were harvested, washed once in TBS $(25 \mathrm{mM}$ Tris $/ \mathrm{HCl}, \mathrm{pH} 7 \cdot 5,135 \mathrm{mM}$ $\mathrm{NaCl}, 2.7 \mathrm{mM} \mathrm{KCl}$ ) and frozen at $-70{ }^{\circ} \mathrm{C}$ until use. Frozen cells suspended in $100 \mu \mathrm{l}$ GTE $(25 \mathrm{mM}$ Tris $/ \mathrm{HCl}, \mathrm{pH} 7 \cdot 5$, $50 \mathrm{mM}$ glucose, $10 \mathrm{mM}$ EDTA) were lysed with lysozyme at a final concentration of $2 \mathrm{mg} \mathrm{ml}^{-1}$ at room temperature for $5 \mathrm{~min}$, then boiled in $0.4 \mathrm{M}$ Tris $/ \mathrm{HCl}, \mathrm{pH} 6 \cdot 8,2 \%$ SDS, $0.5 \%$ $\beta$-mercaptoethanol and $10 \%(\mathrm{v} / \mathrm{v})$ glycerol for $5 \mathrm{~min}$, and separated by centrifugation. The supernatants were used as cell-lysate preparations.

SDS-PAGE and immunoblotting. Protein samples were resolved by SDS-PAGE (10\% acrylamide), and electrotransferred to a PVDF membrane (Immobilon; Millipore). The membrane was incubated overnight at room temperature in phosphate buffered saline/Tween $20(8 \mathrm{mM}$ sodium phosphate, $\mathrm{pH} 7 \cdot 5,150 \mathrm{mM} \mathrm{NaCl}, 0 \cdot 1 \%$ Tween 20), containing $5 \%$ low-fat milk. The membrane was then incubated for $1 \mathrm{~h}$ at room temperature with an anti-FtsY antiserum (at a dilution of 1:5000), in phosphate-buffered saline/Tween 20, followed by an incubation with a secondary antibody conjugated to horseradish peroxidase (Amersham Biotech) at a 1:5000 dilution for $1 \mathrm{~h}$. Immunoblots were washed and visualized using enhanced chemiluminescence reagents, as described by the manufacturer (Amersham Biotech).

Electron microscopy. Wild-type cells (168) and ISR39 grown in Schaeffer medium and harvested at $t_{24}$ were fixed and embedded as described by Nishiguchi et al. (1994), then stained with $1 \%$ uranyl acetate for $30 \mathrm{~min}$ and Reynold's lead
(Hayat, 1972) for $30 \mathrm{~min}$. Stained cells were examined using a JEOL 2000EXII electron microscope.

Immunoelectron microscopy. Wild-type cells at the vegetative stage and during sporulation $\left(t_{18}\right)$ were harvested by centrifugation and suspended in $1.0 \mathrm{ml}$ phosphate-buffered Karnovsky's fixative (Karnovsky, 1965) at room temperature for $1.5 \mathrm{~h}$. Fixed cells were washed once in $0.5 \mathrm{M} \mathrm{NH}_{4} \mathrm{Cl}$, suspended in hot solubilized $1 \%$ Bacto agar in water, gelatinized, then sequentially dehydrated at $4{ }^{\circ} \mathrm{C}$ for $15 \mathrm{~min}$ each in 50, 70, 80, 90 and $95 \%$ ethanol, followed by twice in $100 \%$ ethanol at $-20^{\circ} \mathrm{C}$ for $30 \mathrm{~min}$. Thereafter, the cells were washed twice with $100 \%$ acetone at $-20{ }^{\circ} \mathrm{C}$ for $30 \mathrm{~min}$, then placed in Lowicryl HM20/acetone $(1: 3,1: 1,3: 1)$ at $-50{ }^{\circ} \mathrm{C}$ for $1 \mathrm{~h}$ each, followed by $100 \%$ Lowicryl HM20 at $-50^{\circ} \mathrm{C}$ overnight. After adding fresh resin, blocks were polymerized by UV irradiation at $-50^{\circ} \mathrm{C}$ in a gelatinous capsule overnight. The blocks were thin-sectioned (gold-silver sections) using a diamond knife and placed on nickel grids that were subsequently placed on droplets of $1 \%$ glycine, $1 \%$ gelatin for $30 \mathrm{~min}$, then onto a 1:200 dilution of rabbit antiFtsY antibody overnight in a hydrated chamber. The grids were then washed five times by floating on droplets of $10 \mathrm{mM}$ Tris/ $\mathrm{HCl}(\mathrm{pH} 8 \cdot 0), 0 \cdot 1 \mathrm{mM}$ EDTA for $10 \mathrm{~min}$ and incubated with a $1: 100$ dilution of goat anti-rabbit antibodies conjugated to $15 \mathrm{~nm}$ gold particles (Bio-Rad) for $1 \mathrm{~h}$. After a second wash, cells were stained with $1 \%$ uranyl acetate followed by Reynold's lead (Hayat, 1972) for $30 \mathrm{~min}$ each, then examined using a JEOL 2000EXII electron microscope.

\section{RESULTS AND DISCUSSION}

\section{Sporulation-specific transcript of the fts $Y$ gene}

FtsY is one component of the protein-secretion machinery of B. subtilis. Depletion of FtsY leads to defective cell growth and the accumulation of secretory-protein precursors (Oguro et al., 1996). The fts Y gene forms an operon with $r n c S$ and $s m c$. We investigated $f t s Y$ expression during sporulation by Northern hybridization and determined the size of the RNA product as well as the time it appeared in B. subtilis 168 (Fig. 1a). Cultured 168 cells were harvested at various developmental stages and total RNA was extracted for Northern hybridization. The total RNA isolated from cells during vegetative growth, at $t_{-2}$, contained a band of approximately $5.5 \mathrm{~kb}$ that corresponded to a transcript which included three genes (Fig. 1a, lane 1). These results indicated that the three genes are simultaneously transcribed during exponential phase with two upstream genes $(r n c S$ and $s m c)$ by a putative $\sigma^{\mathrm{A}}$-containing RNA polymerase.

At $t_{0}$, the $5.5 \mathrm{~kb}$ band had disintegrated (Fig. 1a, lane 2) and it was undetectable in cultures $2-6 \mathrm{~h}$ after the end of the exponential phase of growth $\left(t_{2}-t_{6}\right)$ (Fig. 1a, lanes 3 to 5). This rapid disappearance of the $5.5 \mathrm{~kb}$ band may be caused by specific degradation after $t_{0}$, in addition to reduced RNA production, since no obvious breakdown of $16 \mathrm{~S}$ and $23 \mathrm{~S}$ rRNAs was evident in the same samples (data not shown). At $t_{8}$ on the other hand, a $1.7 \mathrm{~kb}$ band containing fts $\mathrm{Y}$ mRNA appeared (Fig. 1a, lane 6). We analysed transcripts of spore-coat proteins expressed during sporulation by Northern hybridization to compare the timing of fts $Y$ expression with that of $\cot Y$ and $\cot Z$ as markers, since Zhang et al. (1994) reported that 
(a)

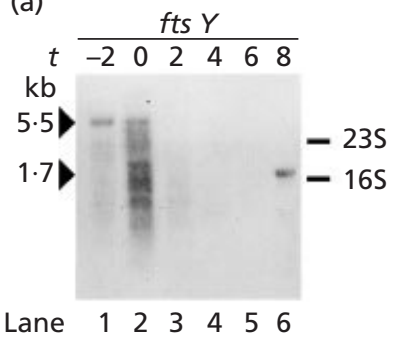

(b)

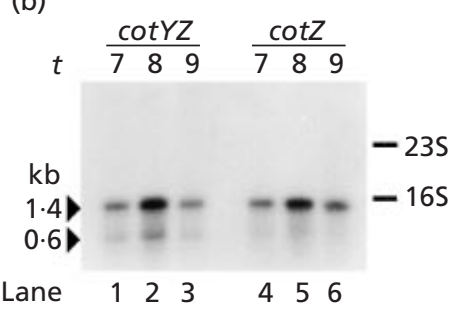

(c)

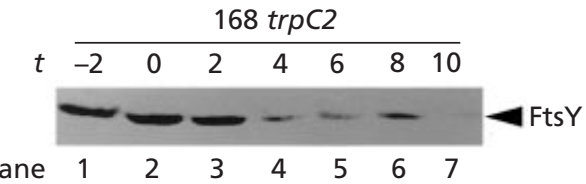

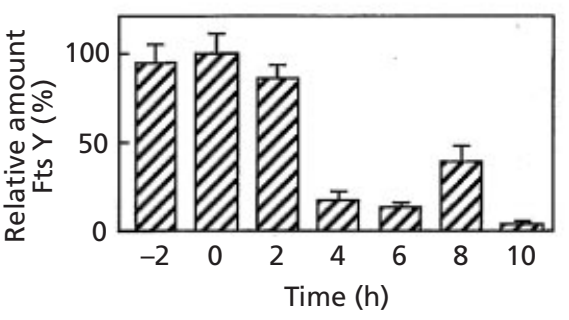

Fig. 1. Expression of the $f t s Y$ gene. (a) Northern hybridization of $f t s Y$ mRNA. Total RNA was extracted from wild-type (B. subtilis 168) cells in Schaeffer medium cultured for $t_{-2}$ (lane 1), $t_{0}$ (lane 2$), t_{2}$ (lane 3$), t_{4}$ (lane 4), $t_{6}$ (lane 5 ) and $t_{8}$ (lane 6). Total RNA $(10 \mu \mathrm{g})$ was analysed using a radiolabelled, nick translated $1061 \mathrm{bp}$ DNA fragment of fts $Y$ as the probe. The size of $f t s Y$ mRNA is indicated at the left of the figure. (b) Expression of $\cot Y Z$ and $\cot Z$ during sporulation. Since $\cot Y Z$ and $\cot Z$ are specifically expressed during sporulation (Zhang et al., 1994), total RNAs of wild-type cells cultured until $t_{7}$ (lanes 1 and 4 ), $t_{8}$ (lanes 2 and 5 ) and $t_{9}$ (lanes 3 and 6) were extracted, blotted and probed with a 1150 bp DNA fragment of $\cot Y Z$ and a $569 \mathrm{bp}$ DNA of cotZ, respectively. (c) Immunoblot of FtsY expressed in B. subtilis 168. B. subtilis 168 was cultured in Schaeffer medium harvested at $t_{-2}$ (lane 1), $t_{0}$ (lane 2$), t_{2}$ (lane 3$), t_{4}$ (lane 4$), t_{6}$ (lane 5), $t_{8}($ lane 6) and $t_{10}$ (lane 7$)$ and lysed. Total proteins $(20 \mu \mathrm{g})$ from each preparation were resolved by SDS-PAGE and immunoblotted against anti FtsY antiserum. The arrow indicates the position of FtsY. The lower part of (c) indicates the relative amount of each Fts $Y$ band when the $t_{0}$ band density corresponds to 100 .

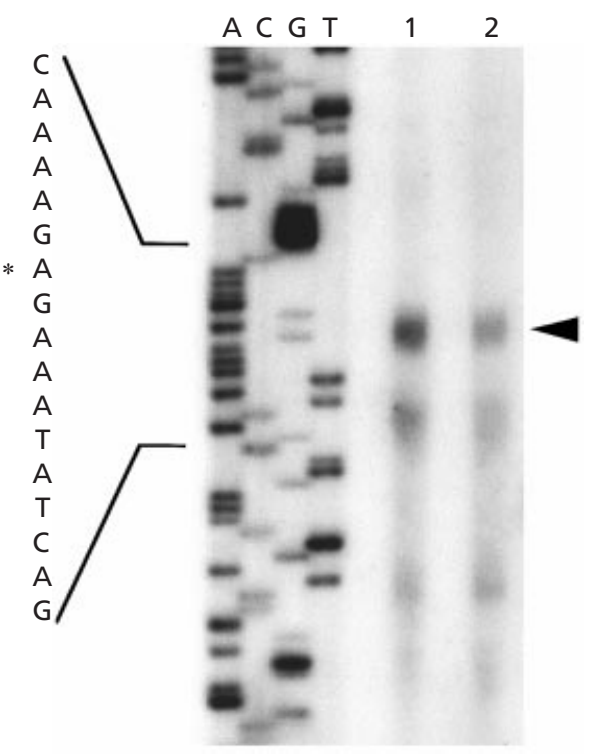

Fig. 2. Determination of the transcription-initiation site by primer-extension analysis. Total RNAs $(40 \mu \mathrm{g})$ from $B$. subtilis 168 cultured in Schaeffer medium at $t_{8}$ (lane 1) and $t_{9}$ (lane 2) were hybridized with a labelled $\mathrm{Pr}$ primer that was complementary to nucleotides $4339-4358$ in the sequence shown in Fig. 3. Primer-extended products obtained with reverse transcriptase were resolved by electrophoresis through $8 \%$ polyacrylamide sequencing gels, then visualized by autoradiography. DNA sequencing reaction mixtures containing the $\mathrm{Pr}$ primer and a single stranded DNA from the M13 derivative as the template, were resolved by electrophoresis in parallel (lanes A, C, G and T). Positions of the major product is indicated by an arrowhead. The asterisk in the sequence shows the estimated position of the transcription-initiation site. $\cot \mathrm{Y}$ and $\cot \mathrm{Z}$ are co-transcribed by $\sigma^{\mathrm{K}}$-containing RNA polymerase from the $\mathrm{P}_{\mathrm{YZ}}$ promoter with a smaller $\cot Y \mathrm{mRNA}$ resulting from premature termination or RNA processing. We detected two bands $(1.4$ and $0.6 \mathrm{~kb})$ in total RNAs at $t_{7}, t_{8}$ and $t_{9}$ using the $1150 \mathrm{bp}$ DNA probe for $\cot Y Z$, but only one $1.4 \mathrm{~kb}$ band using the 569 bp DNA probe for $\cot Z$ (Fig. 1b). The density of the 1.4 and $0.6 \mathrm{~kb}$ bands indicated that $\cot Y Z$ expression was maximal at $t_{8}$ under our culture conditions. This period of $\cot Y Z$ expression coincided with that of $f t s Y$.

We then analysed the amounts of Fts $Y$ in lysates of $B$. subtilis 168 by immunoblotting. Bands for FtsY were intense at $t_{-2}$ and $t_{0}$. However, the density decreased after $t_{0}$ (Fig. 1c, lanes 3-5). At $t_{8}$, which is the period of fts $Y$ expression (Fig. 1a), the FtsY band was again detected, but at a density that was $2 \cdot 5$-fold higher than that at $t_{6}$ (Fig. 1c, lane 6). This result is consistent with the findings of the Northern hybridization (Fig. 1a). After $t_{8}$, the amount of FtsY again decreased and the band was very faint at $t_{10}$ (Fig. 1c, lane 7). On the other hand, at $t_{2}$ (Fig. 1a), the amounts of FtsY protein were substantial, whereas $f t s \mathrm{mRNA}$ is virtually absent (Fig. $1 \mathrm{a}$, lane 3 and Fig. 1c, lane 3 ). These data suggest that the half-life of FtsY protein is relatively long.

\section{Mapping the $5^{\prime}$ terminus of $f t s Y$ mRNA expressed during sporulation}

To define the $5^{\prime}$ terminus of the $1.7 \mathrm{~kb}$ transcript of $f t s Y$ found at $t_{8}$ (Fig. 1a), we performed primer-extension analysis using the synthetic oligonucleotide $\operatorname{Pr}$ (see Methods). The primer-extension product is indicated by 
$5.5 \mathrm{~kb}$
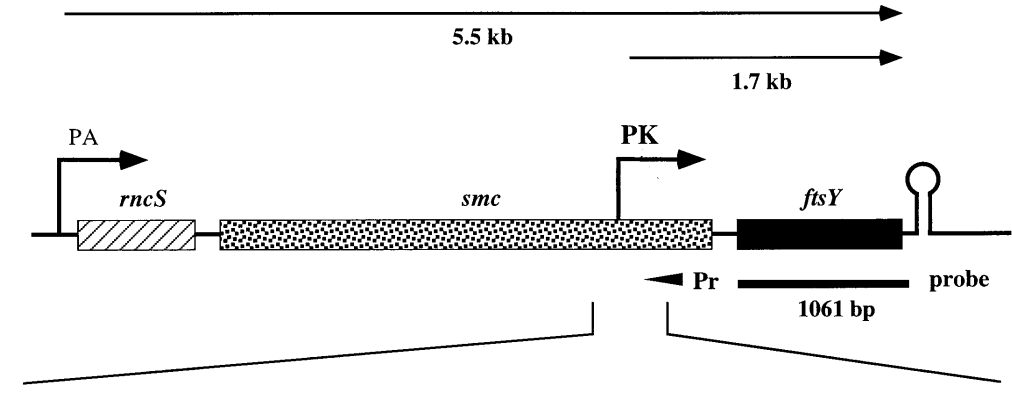

AGAAATGAAACGCCTGTATAAACAAAAAACAACGCTCTTAAAAGACGAAGAAGTCAAACT 4160

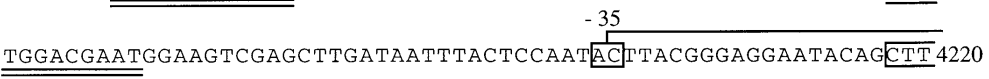

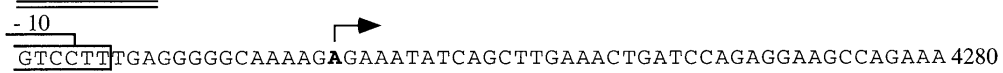

GCGCGTGAAGCTGATTAAACTCGCAATTGAagGCTGGGTACCGTGAACCTCGGAAGCAT

GCGCGTGAAGCTGATTAAACTCGCAATTGAAGAGCTGGGTACCGTGAACCTCGGAAGCAT 4340 $\operatorname{Pr}$

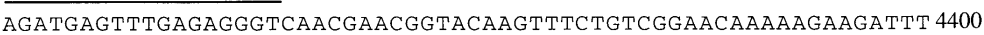

Fig. 3. Schematic representation of the $f t s Y$ gene expression. The third gene of the fts $Y$ operon is fts $Y$ and its expression is controlled by two promoters (PA and PK) as indicated by Northern hybridization (Fig. 1a) and by the primer-extension analysis of the $1.7 \mathrm{~kb}$ ftsY mRNA (Fig. 2). The positions and lengths of each mRNA are controlled by the two promoters shown above. Nucleotide sequences of the putative PK promoter and the transcription-initiation site are shown below. Nucleotide numbers are as reported by Oguro et al. (1996). $\mathrm{Pr}$ is a synthetic oligonucleotide used as the primer to map the $5^{\prime}$ terminus of $f t s Y$ mRNA. Putative GerEbinding regions are double underlined.

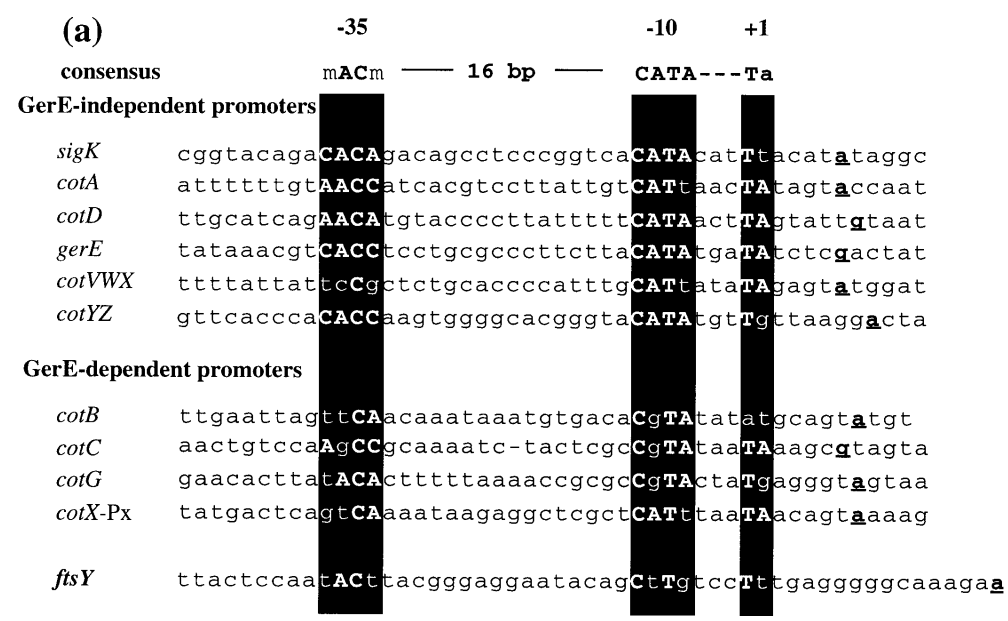

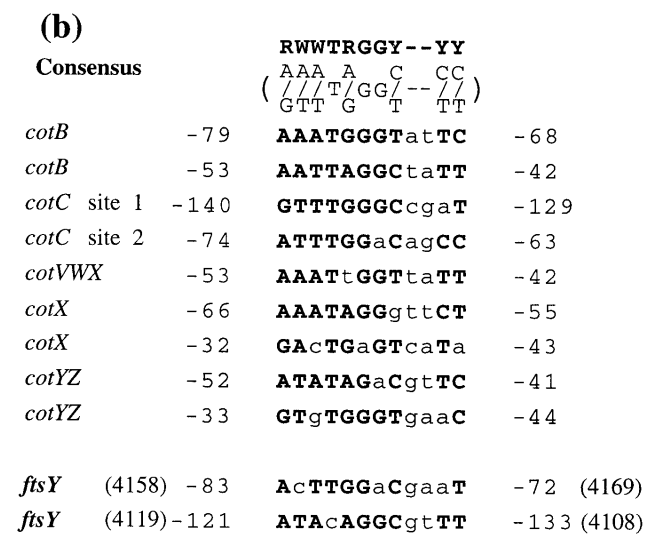

Fig. 4. Sequence comparison of the PK promoter of $f t s Y$ with promoter regions transcribed by $\sigma^{\mathrm{K}}$-containing RNA polymerase. (a) Alignment of nucleotide sequences for promoter regions transcribed by $\sigma^{\mathrm{K}}$-containing RNA polymerase. Promoters for six genes transcribed in the absence of GerE and four genes for which transcription required GerE in addition to $\sigma^{\mathrm{K}}$ are shown separately. Nucleotides in each promoter that match the consensus sequence (bold face and capital letters) are shown between the groups $(m=C$ or $A)$. Bold face and underlined nucleotides correspond to the transcription-start point. Sequences for the PK putative promoter region for fts $Y$ (Fig. 3) are shown with matches to the consensus indicated by capital letters. (b) Alignment of nucleotide sequences of GerE-binding sites upstream of cotB, cotC, $\operatorname{cotVWX}$, cotX and cotYZ promoter (Zhang et al., 1994; Zheng et al., 1992). Sequences thought to be GerE-binding sites for the PK promoter region of fts $Y$ are shown (4108-4119 and 4158-4169). $\mathrm{R}=\mathrm{A}$ or $\mathrm{G} ; \mathrm{W}=\mathrm{A}$ or $\mathrm{T} ; \mathrm{Y}=\mathrm{T}$ or $\mathrm{C}$.

an arrow and two smaller minor products are visible in Fig. 2. These minor products could have resulted from premature termination by the reverse transcriptase. The largest extension product indicated by an arrowhead (Fig. 2) corresponded to the $5^{\prime}$ terminus of the $1.7 \mathrm{~kb}$ transcript of $f t s \mathrm{YRNA}$ during sporulation. This transcript was more abundant in RNA from cells harvested at $t_{8}$ than at $t_{9}$. The $5^{\prime}$ terminus of the fts $Y$ mRNA was located 705 bp upstream of the translationinitiation site for the fts Y ORF, inside the smc gene (Fig. 3 ). These results indicated that $f t s \mathrm{Y}$ is transcribed solely via the putative promoter (PK) during sporulation, since the $f t s Y$ gene is $987 \mathrm{bp}$ long and a $\rho$-independent transcriptional terminator is located downstream of the stop codon of $f t s Y$. The nucleotide sequence around the PK promoter (4199-4226 region) was similar to the consensus sequence of the -35 (AC) and -10 (CATA - - Ta) promoter region recognized by $B$. subtilis RNA polymerase containing $\sigma^{\mathrm{K}}$ (Fig. 4a) (Roels \& Losick, 1995; Zhang et al., 1994; Zheng et al., 1992). Fig. 4(a) shows that the nucleotide sequences of GerEindependent promoters closely match the consensus 

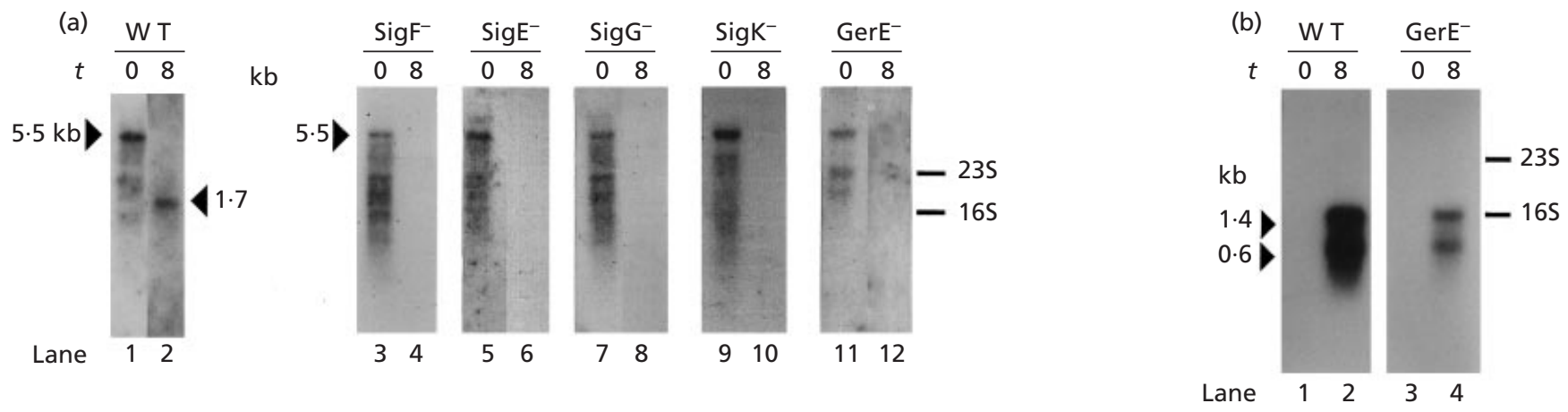

Fig. 5. Transcription of $f t s Y$ in $B$. subtilis wild-type strain 168 and sigma mutants. (a) Northern hybridization of $f t s Y$ mRNA in $\sigma^{\mathrm{E}}, \sigma^{\mathrm{F}}, \sigma^{\mathrm{G}}, \sigma^{\mathrm{K}}$ and gerE mutants. Total RNA was extracted from wild-type (B. subtilis 168) (lanes 1 and 2 ), MO719 $\left(\mathrm{SigF}^{-}\right.$) (lanes 3 and 4), MO1781 (SigE ${ }^{-}$) (lanes 5 and 6), MO718 (SigG ${ }^{-}$) (lanes 7 and 8), MO1027 (SigK ${ }^{-}$) (lanes 9 and 10) and $1 \mathrm{G} 12\left(\mathrm{GerE}^{-}\right.$) (lanes 11 and 12) cells cultured in Schaeffer medium for $t_{0}$ (lanes 1, 3, 5, 7, 9 and 11) and $t_{8}$ (lanes 2, 4, $6,8,10$ and 12). (b) Northern hybridization of $\cot Y Z$ and $\cot Z$ mRNA in gerE mutants. Total RNA extracted from wild-type (B. subtilis 168) (lanes 1 and 2 ) and $1 \mathrm{G} 12\left(\mathrm{GerE}^{-}\right)$(lanes 3 and 4) cells was blotted and probed with a $1 \cdot 1 \mathrm{~kb}$ DNA fragment of $\cot Y Z$.

sequence, whereas the sequences of GerE-dependent promoters generally have little resemblance (Roels \& Losick, 1995). The nucleotide sequence of the -10 region of the PK promoter has low identity with the consensus sequence of the $\sigma^{\mathrm{K}}$ promoter, which is consistent with the fact that $f t s Y$ transcription during sporulation is regulated in a GerE-dependent manner. We identified putative GerE-binding sequences (4110$4121 \mathrm{bp}$ and $4160-4171 \mathrm{bp}$ ) upstream from the PK promoter (Figs 3 and $4 \mathrm{~b}$ ). These data suggest that $f t s Y$ is transcribed by PK promoters during sporulation as shown in the upper part of Fig. 3.

\section{Regulation of the $f t s Y$ gene during sporulation}

To examine which $\sigma$ factor relates to $f t s Y$ transcription at $t_{8}$, RNAs from the sigma factor-deficient strains

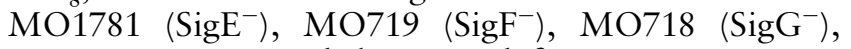
MO1027 (SigK $\left.{ }^{-}\right)$and the GerE-deficient strain, 1G 12, were extracted at $t_{0}$ and $t_{8}$, and hybridized using the $1061 \mathrm{bp}$ DNA fragment encoding $f t s Y$ as the probe (Fig. $5 \mathrm{a}$ ). The $5.5 \mathrm{~kb}$ band found in B. subtilis 168 (Fig. $5 \mathrm{a}$, lane 1), including the two upstream genes, was detected in all total RNA samples isolated at $t_{0}$ (Fig. 5a, lanes 3, $5,7,9$ and 11). The lower-molecular-mass bands may be degradation products of the $5.5 \mathrm{~kb}$ transcript. In contrast, the $1.7 \mathrm{~kb}$ bands found in the RNA preparation of wild-type cells at $t_{8}$ (Fig. 5a, lane 2), were not detected in preparations of the $\sigma^{\mathrm{E}}, \sigma^{\mathrm{F}}, \sigma^{\mathrm{G}}, \sigma^{\mathrm{K}}$ and gerE mutant cells sampled at $t_{8}$ (Fig. 5a, lanes 4, 6, 8, 10 and 12). Under these conditions, we detected reduced levels of $\cot Y$ and $\cot Z$ transcripts in RNA preparations derived from gerE mutant cells at $t_{8}$ (Fig. 5b), compared with the wild-type. Zhang et al. (1994) reported that the expression of $\cot Y$ and $\cot Z$ is under the control of $\sigma^{\mathrm{K}}$-containing RNA polymerase and GerE. No obvious bands corresponded to $\cot Y$ and $\cot Z$ in the $\sigma^{\mathrm{K}}$ mutant. However, lower levels of $\cot Y$ and $\cot Z$ transcripts were detected in the
gerE mutant compared with the wild-type. These results are all in good agreement. We detected transcripts of $\cot Y$ and $\cot Z$ in RNA preparations derived from gerE mutant cells at $t_{8}$, indicating that the disappearance of $1.7 \mathrm{~kb}$ band corresponding to $f t s \mathrm{Y}$ is not due to substantial degradation of RNA by RNases during preparation.

\section{Effects of depletion of FtsY on spore morphology}

To analyse the effect of Fts Y depletion upon sporulation, we prepared a conditional null mutant of $f t s Y$ that expresses $f t s \mathrm{Y}$ during the vegetative stage, but not during sporulation. Plasmid pMT3FtsY, which does not have a replication origin for $B$. subtilis, was integrated into the $B$. subtilis chromosome by single reciprocal recombination. The gene organization around $f t s Y$ of transformant strain ISR39 (Fig. 6a) was determined by Southern hybridization and PCR (data not shown). The strain ISR39 has three $\rho$-independent transcriptional terminators upstream of the spac-1 promoter to avoid transcription of the $f t s Y$ gene from both the $\sigma^{\mathrm{A}}(\mathrm{PA})$ and PK promoters. Expression of intact $f t s Y$ gene in this strain should be regulated by only the IPTG-inducible promoter spac-1, of which the nucleotide sequences of -35 and -10 regions are typical of a $\sigma^{\mathrm{A}}$ promoter. Therefore, in the presence of a low concentration of IPTG, the fts $Y$ gene can be expressed during the vegetative stage, but not during sporulation. We measured the amount of FtsY and the growth of ISR39 cells cultured in the presence of $0 \cdot 1 \mathrm{mM}$ IPTG. Immunoblotting detected normal levels of FtsY during logarithmic cell growth when cells were cultured in the presence of $0.1 \mathrm{mM}$ IPTG. (Fig. 6c, lanes 1 and 2). The growth of ISR39 was impaired in the absence of IPTG (data not shown), in agreement with published results showing that FtsY is essential for growth (Oguro et al., 1996). We then investigated the expression of $f t s Y$ 


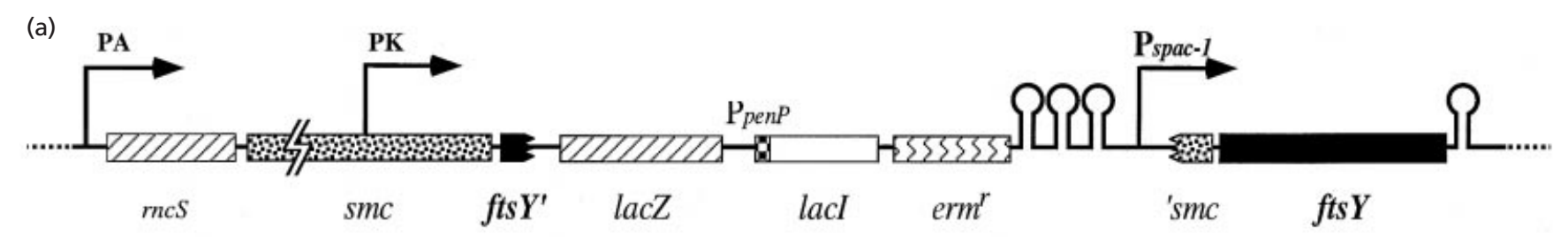

B. subtilis ISR39 chromosome

(b)

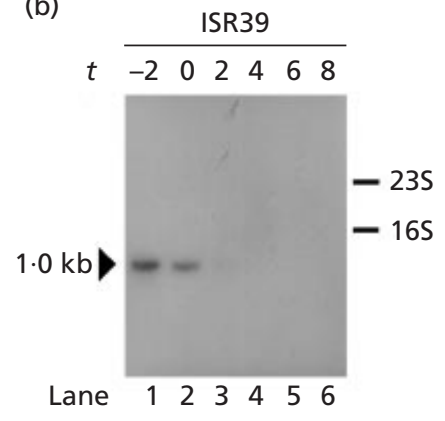

(c)
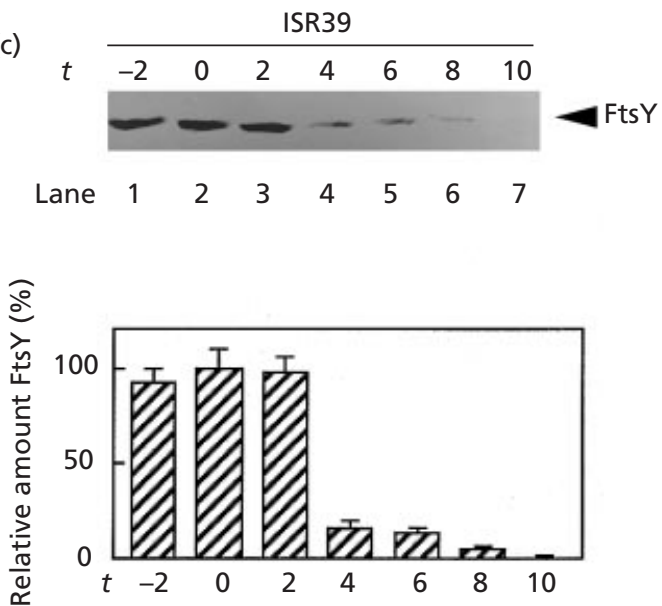

Fig. 6. Structure of $B$. subtilis ISR39 strain in which $f t s Y$ expression is dependent on IPTG, and expression of the $f t s Y$ gene in ISR39. (a) Schematic representation of the gene structure around fts $Y$ in the $B$. subtilis ISR39 chromosome. Inserted genes were localized by DNA-DNA hybridization and by examining PCR products. Integrating the E. coli plasmid, pMT3Fts $Y$, into the $f t s Y$ locus results in a truncated $f t s Y$ gene $\left(f t s Y^{\prime}\right)$ under the control of authentic PA and PK and an intact copy of $\mathrm{fts} Y$ under the control of the spac-1 promoter (Pspac-1). $\Omega$, $\rho$-independent transcriptional terminator. (b) Northern hybridization of fts $Y$ mRNA in $B$. subtilis ISR39. Total RNA was extracted from ISR39 cells cultured in Schaeffer medium in the presence of $0.1 \mathrm{mM}$ IPTG. Conditions were as described in the legend to Fig. 1. The size of the predicted $\mathrm{fts} Y$ mRNA is indicated on the left. (c) Immunoblots of FtsY expression in ISR39. B. subtilis ISR39 cells were cultured in Schaeffer medium and harvested at $t_{-2}$ (lane 1), $t_{0}$ (lane 2$), t_{2}$ (lane 3$), t_{4}$ (lane 4), $t_{6}$ (lane 5), $t_{8}$ (lane 6) and $t_{10}$ (lane 7). The arrow indicates the position of FtsY.

during exponential growth and sporulation by Northern hybridization, to define the size of the RNA product and determine when it appeared in B. subtilis ISR39 in the presence of $0 \cdot 1 \mathrm{mM}$ IPTG. We detected a $1 \cdot 0 \mathrm{~kb}$ band at $t_{-2}$ and $t_{0}$ (Fig. 6b, lanes 1 and 2). This product is the expected size resulting from transcription from the spac1 promoter. However, the fts $Y$ transcript was not detected at $t_{4}-t_{8}$ (Fig. 6b, lanes 4-6). We monitored the level of FtsY protein by immunoblotting during sporulation under the same conditions (Fig. 6c, upper panel). In ISR 39 cells, FtsY protein was present at $t_{-2}-t_{2}$ (Fig. 6c, lanes 1-3) and the level of FtsY decreased at $t_{4}-t_{6}$ (Fig. $6 \mathrm{c}$, lanes 4 and 5). This timing is similar to that seen in the parent strain 168 (Fig. 1c). However, at $t_{8}$, FtsY was barely detectable in ISR 39. These results indicated that in the presence of IPTG, ISR39 cells do not express the $f t s Y$ gene which is under control of the $\sigma^{\mathrm{K}}$ promoter (Fig. 6c, lane 7).

A recent review (Driks, 1999) demonstrated four steps in spore-coat assembly that proceed in a defined temporal order and these are mainly regulated by the successive appearance of the regulatory proteins $\sigma^{\mathrm{E}}$, spoIIID, $\sigma^{\mathrm{K}}$ and GerE. Spore-coat polypeptides are synthesized only in the mother-cell compartment, starting after 3-4 h of sporulation $\left(t_{3}-t_{4}\right)$ and are individually deposited on the surface of the prespore. The finding that transcription of $f t s Y$ depends on both $\sigma^{\mathrm{K}}$ and GerE suggested that Fts $\mathrm{Y}$ protein is required for inner and outer coat layer assembly that includes post-assembly modification of the coat protein. We examined the ultrastructure of the $\mathrm{fts} Y$ mutant spores by electron microscopy. In wild-type 168 spores, the coat appeared to consist of a thick, dense outer multilayer and a lamella inner coat (Fig. 7a and c). Compared with spores produced by the parental strain, $80 \%$ of 150 Fts Y-depleted mutant spores had a thin and somewhat disorganized outer coat structure (Fig. $7 \mathrm{~b}$ and d). These morphological changes have also been found in $\cot X Y Z$ triple mutant and $\cot M$ mutant spores (Henriques et al., 1997; Zhang et al., 1993). At $t_{48}$, the fts $Y$ mutant spores assumed the same form as they did at $t_{24}$ (data not shown). This is not due to delayed sporulation in the $f t s Y$ mutant cells. Considerably less material appeared to be assembled in the surface layers of the outer coat of ISR39 spores. The appearance of this lamella-type structure of lower electron density was very 

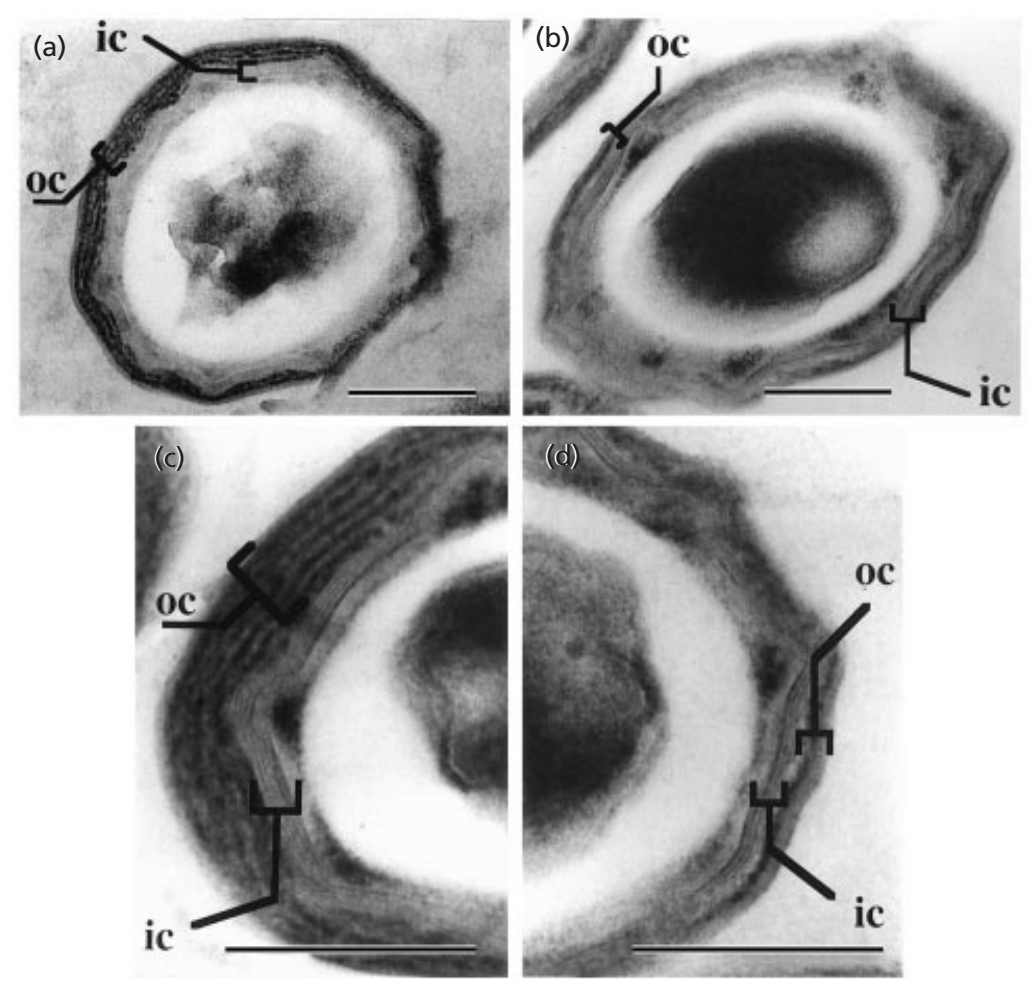

Fig. 7. Electron microscopy of 168 and ISR39 spores. Electron micrographs show sections of 168 (a and c) and ISR39 (the ftsY conditional null mutant, $b$ and d). ISR39 spores have an anomalous morphological arrangement. Densely stained outer coat (oc) is incomplete in ISR39. In contrast, the inner coat (ic) of wild-type and mutant spores are similarly constructed. Cells cultured in sporulation medium were harvested at $t_{24}$. Bars, $200 \mathrm{~nm}$.
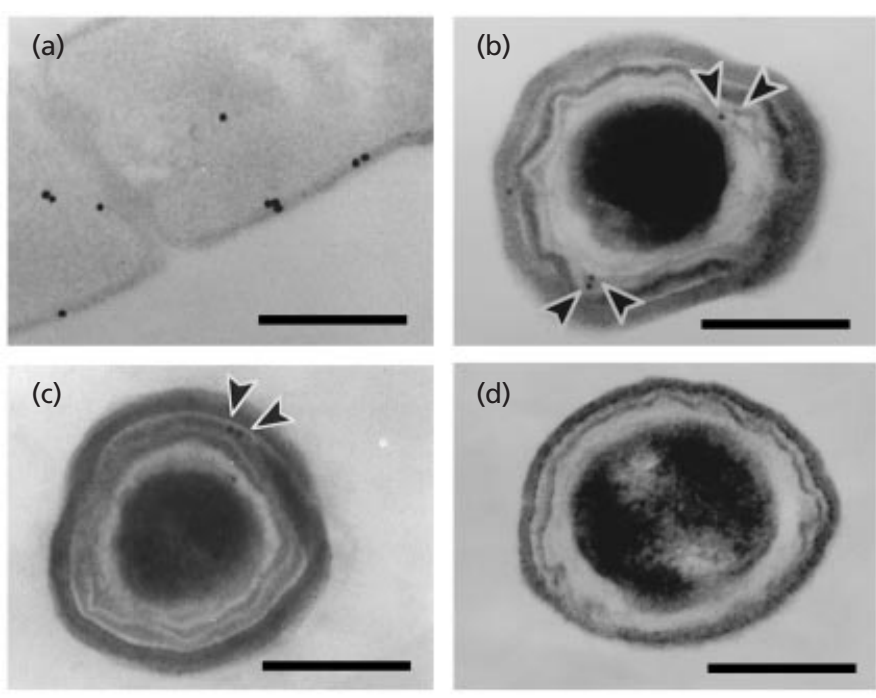

Fig. 8. Subcellular localization of FtsY in vegetative cells and spores. Vegetative cells of wild-type at $t_{-2}(a)$, sporulating cells of wild-type at $t_{18}$ (b and $c$ ) and the $f t s Y$ conditional null mutant at $t_{18}(\mathrm{~d})$ were thin-sectioned and incubated with rabbit anti-FtsY antibody followed by a gold-conjugated secondary antibody, as described in Methods. Dark specks on electron micrographs are gold particles. Bars, $200 \mathrm{~nm}$. Arrowheads indicate FtsY on the coat.

similar to that typical of the inner coat layers. In addition, we analysed the effect of $f t s Y$ upon sporulation by measuring the sporulation frequency of ISR39 cells that were cultured in the presence of $0.1 \mathrm{mM}$ IPTG and harvested at $t_{24}$. Samples were plated following with or without heating at $80{ }^{\circ} \mathrm{C}$ for $15 \mathrm{~min}$. The sporulation frequency of the mutant appeared to be almost identical to that of the wild-type (data not shown).

\section{Immunocytochemical localization of FtsY}

To analyse the subcellular localization of FtsY proteins in vegetative cells and spores, B. subtilis 168 and ISR39 cells at the vegetative stage and at $t_{18}$ were thinsectioned. FtsY proteins were then observed by immunoelectron microscopy using rabbit anti-FtsY antiserum and goat antibodies conjugated to gold particles. Gold granules were found in both the cytoplasm and cytoplasmic membranes of vegetative wild-type cells (Fig. 8a). Gold granules were not found in vegetative cells of ISR39 in the absence of IPTG (data not shown). We counted gold granules in the cytoplasm and membrane of 25 cells. FtsY was localized in the cytoplasm and membrane at an approximate ratio of $2: 3$. This result was similar to that found by cell fractionation (data not shown). In E. coli, FtsY, a homologue of the $\alpha$ subunit of the mammalian SRP receptor, is functional at both the cytoplasm and membrane at an approximate ratio of 1:1 (Luirink et al., 1994). FtsY in spores was predominantly located on the inner and outer coats (Fig. 8b and c) where they would have been brought to the forespores from mother cells. In ISR 39 spores cultured in the presence of $0.1 \mathrm{mM}$ IPTG, gold granules were not localized on the coat regions (Fig. 8d). In contrast, gold granules located in the core region would be expressed before the polar septum is formed and would have remained in the core region during sporulation. 
These results suggest that FtsY participates in sporecoat assembly or that Fts Y function is needed for the assembly of other proteins. Further study is necessary to determine the physiological roles of Fts Y in spore-coatprotein assembly.

\section{ACKNOWLEDGEMENTS}

We thank N. Foster for critical reading of the manuscript. We are grateful to Patrick Stragier for providing the sigma mutant strains MO718, MO719, MO1027 and MO1781. We thank Shigeki Moriya for providing pMutinT3.

This study was supported in part by Grants-in-Aid for scientific research from the Ministry of Education, Science and Culture of Japan. Electron microscopy was supported by the TARA (Tsukuba Advanced Research Alliance) project of Tsukuba University.

\section{REFERENCES}

Driks, A. (1999). Bacillus subtilis spore coat. Microbiol Mol Biol Rev 63, 1-20.

Fekkes, P. \& Driessen, A. J. M. (1999). Protein targeting to the bacterial cytoplasmic membrane. Microbiol Mol Biol Rev 63, 161-173.

Hayat, M. A. (1972). Basic Electron Microscopy Techniques. New York: Van Nostrand Reinhold.

Henriques, A. O., Beall, B. W. \& Moran, C. P., Jr (1997). CotM of Bacillus subtilis, a member of the $\alpha$-crystallin family of stress proteins, is induced during development and participates in spore outer coat formation. J Bacteriol 179, 1887-1897.

Honda, K., Nakamura, K., Nishiguchi, M. \& Yamane, K. (1993). Cloning and characterization of a Bacillus subtilis gene encoding a homolog of the 54 kilodalton subunit of mammalian signal recognition particle and Escherichia coli Ffh. J Bacteriol 175, 4885-4894.

Igo, M. M. \& Losick, R. (1986). Regulation of a promoter that is utilized by minor forms of RNA polymerase holoenzyme in Bacillus subtilis. J Mol Biol 191, 615-624.

Karnovsky, M. J. (1965). A formaldehyde-glutaraldehyde fixative of high osmolarity for use in electron microscopy. J Cell Biol 27, 137A-138A.

Kunst, F., Ogasawara, N., Moszer, I. \& 148 other authors. (1997). The complete genome sequence of the Gram-positive bacterium Bacillus subtilis. Nature 390, 249-256.

Losick, R. \& Stragier, P. (1992). Crisscross regulation of cell-typespecific gene expression during development in B. subtilis. Nature 355, 601-604.

Lütcke, H. (1995). Signal recognition particle (SRP), a ubiquitous initiator of protein translocation. Eur J Biochem 228, 531-550.
Luirink, J., ten Hagen-Jongman, C. M., van der Weijden, C. C., Oudega, B., High, S., Dobberstein, B. \& Kusters, R. (1994). An alternative protein targeting pathway in Escherichia coli: studies on the role of FtsY. EMBO J 13, 2289-2296.

Moriya, S., Tsujikawa, E., Hassan, A. K., Asai, K., Kodama, T. \& Ogasawara, N. (1998). A Bacillus subtilis gene encoding protein homologous to eukaryotic SMC motor protein is necessary for chromosome partition. Mol Microbiol 29, 179-187.

Nakamura, K., Imai, Y., Nakamura, A. \& Yamane, K. (1992). Small cytoplasmic RNA of Bacillus subtilis: functional relationship with human signal recognition particle 7S RNA and Escherichia coli 4.5S RNA. J Bacteriol 174, 2185-2192.

Nishiguchi, M., Honda, K., Amikura, R., Nakamura, K. \& Yamane, K. (1994). Structural requirements of Bacillus subtilis small cytoplasmic RNA for cell growth, sporulation, and extracellular enzyme production. J Bacteriol 176, 157-165.

Oguro, A., Kakeshita, H., Honda, K., Takamatsu, H., Nakamura, K. \& Yamane, K. (1995). srb: a Bacillus subtilis gene encoding a homologue of the $\alpha$-subunit of the mammalian signal recognition particle receptor. DNA Res 2, 95-100.

Oguro, A., Kakeshita, H., Takamatsu, H., Nakamura, K. \& Yamane, K. (1996). The effect of Srb, a homologue of the mammalian SRP receptor $\alpha$-subunit, on Bacillus subtilis growth and protein translocation. Gene 172, 17-24.

Roels, S. \& Losick, R. (1995). Adjacent and divergently oriented operons under the control of the sporulation regulatory protein GerE in Bacillus subtilis. J Bacteriol 177, 6263-6275.

Sambrook, J., Fritsch, E. F. \& Maniatis, T. (1989). Molecular Cloning: a Laboratory Manual, 2nd edn. Cold Spring Harbor, NY: Cold Spring Harbor Laboratory.

Schaeffer, P., Millet, J. \& Aubert, J. P. (1965). Catabolite repression of bacterial sporulation. Proc Natl Acad Sci U S A 54, 704-711.

Schatz, G. \& Dobberstein, B. (1996). Common principles of protein translocation across membranes. Science 271, 1519-1526.

Stragier, P. \& Losick, R. (1996). Molecular genetics of sporulation in Bacillus subtilis. Annu Rev Genet 30, 297-341.

Struck, J. C. R., Hartmann, R. K., Toschka, H. Y. \& Erdmann, V. A. (1989). Transcription and processing of Bacillus subtilis small cytoplasmic RNA. Mol Gen Genet 215, 478-482.

Zhang, J., Fitz-James, P. C. \& Aronson, A. I. (1993). Cloning and characterization of a cluster of genes encoding polypeptides present in the insoluble fraction of the spore coat of Bacillus subtilis. J Bacteriol 175, 3757-3766.

Zhang, J., Ichikawa, H., Halberg, R., Kroos, L. \& Aronson, A. I. (1994). Regulation of the transcription of a cluster of Bacillus subtilis spore coat genes. J Mol Biol 240, 405-415.

Zheng, L., Halberg, R., Roels, S., Ichikawa, H., Kroos, L. \& Losick, R. (1992). Sporulation regulatory protein GerE from Bacillus subtilis binds to and can activate or repress transcription from promoters for mother-cell-specific genes. J Mol Biol 226, $1037-1050$

Received 21 February 2000; revised 12 June 2000; accepted 3 July 2000. 